\title{
Primary Large Hydatid Cyst of The Neck
}

\section{El Bousaadani A*, Eljahd L, Lezrag M, Elfakiri M, Abada R, Rouadi S, Roubal M and Mahtar M}

Department of ENT, "20 August” Hospital, Ibn Rochd University Hospital, Casablanca, Faculty of Medicine and Pharmacy, Casablanca, Morocco

${ }^{*}$ Corresponding author: El Bousaadani A, ENT Service and Neck Surgery. Ibn Rushd Chu, Casablanca, Morocco, Tel: 00212663503639, E-mail: elbousaadani@gmail.com

Citation: El Bousaadani A, Eljahd L, Lezrag M, Elfakiri M, Abada R, et al. (2015) Primary Large Hydatid Cyst of The Neck. J Case Rep Stud 3(6): 603. doi: 10.15744/2348-9820.3.603

Received Date: September 27, 2015 Accepted Date: December 12, 2015 Published Date: December 15, 2015

\begin{abstract}
Hydatid cyst in the head and neck is very rare. We report the exceptional case of a 9-year-old female child presenting with a hydatid cyst in the posterior cervical region. The diagnosis of hydatid cyst is made mainly with the help of imaging methods and review of the patient's history. Serologic tests can also be useful. The treatment is surgical. Postoperative Albendazole therapy is suggested especially when there is a high preoperative contamination risk.
\end{abstract}

Keywords: Echinococcus granulosus; Hydatid cyst; Neck; Child; Parasite

\section{Introduction}

Hydatid cyst is a cyclozoonotic infection caused by the cestode, Echinococcus granulosus. The primary host is the dog. Occasionally hosts are man [1,2]. Hydatid disease has its highest incidence in sheep- and cattle-rearing regions, such as the Mediterranean countries, the Middle East, South America, New Zealand, Australia, and Southeast Asia [3]. It is endemic in Morocco, where close and continuous contact exists among dogs, the definitive host, and sheep, the intermediate host of the parasite [4]. The adult tapeworm, a true hermaphrodite, lives in the intestine of the definitive hosts. Its terminal segment, which contains 500 to 800 eggs, is released into the intestinal tract of the dog and is expelled in dog feces. The intermediate host, sheep or human, swallows the ovum, and the outer shell of the ovum dissolves in the duodenum, liberating an embryo. If the uncooked viscera of sheep are eaten by dogs, protoscolices develop into adult tapeworms, and the life cycle of the parasite is completed $[3,4]$. In the intermediate host, the embryos enter the portal circulation in the intestines and most of them are caught in the liver, whereas some reach the pulmonary arteries. Those entrapped within the lung parenchyma develop cysts in the lungs, whereas some may even pass through the lungs and reach the systemic circulation [1,2]. The most frequently involved organ is the liver (65\%) because most of the embryos are trapped within it [5]. A review of medical literature revealed that Localization in soft tissues is extremely rare accounting for only $2.3 \%$ in the largest published series consisting of only 24 out of 1056 cases. Hydatid cyst of head and neck is rare even in the regions where the disease is endemic, but exact incidence is not known. There are only a very few case reports of a primary hydatid cyst in the neck region [3-12]. We present one case of a hydatid cyst located in the posterolateral cervical region to remind clinicians to consider this disease in the differential diagnosis of cervical masses and to point out the potential pitfalls in the diagnosis and treatment of this rare cervical mass.

\section{Case Report}

A 9-year-old child presented to our ENT and Head and neck service with a 1-year history of a painless, gradually growing mass located in the posterior of the right side of her neck. She had an unremarkable medical history. On physical examination, the 7- $4 \mathrm{~cm}$ mass was painless, not hard, and located in the right jugulodigastric region. It had a smooth surface (Figure 1). The computed tomography (CT) scan of the neck showed a $75^{\star} 45^{\star} 35 \mathrm{~mm}$ cystic mass located at the level of the hyoid bone in the right posterolateral region. The CT findings suggested the diagnosis of hydatid cyst in objectifying a hypodense cystic formation with irregular intrakystique floating membrane (Figure 2). Others evoked diagnosis in this step were a congenital cyst of the neck or a cystic tumor. The mass was thought to be a hydatid cyst and excision of the cyst was planned. Under general anesthesia, the neck was explored. The mass was located on the posterior side of the right trapeze muscle. On palpation, the mass was found to be cystic. The mass was dissected from the surrounding structures easily and excised totally, protecting the integrity of its capsule (Figure 3). On pathologic examination, the mass was found to have daughter cysts and a germinative layer and was diagnosed as hydatid cyst. To exclude the possibility of invasion to the visceral organs, the patient was subjected to CT scan of the thorax, ultrasonography (USG) of the abdomen, and gynecologic examination. The investigations did not reveal any extracervical site for other hydatid cysts. Enzyme-linked immunosorbent assay result was positive. The patient received albendazole ( $400 \mathrm{mg} / \mathrm{d}$ ) for 4 weeks without notable side effects. She has been disease free for 50 months. 


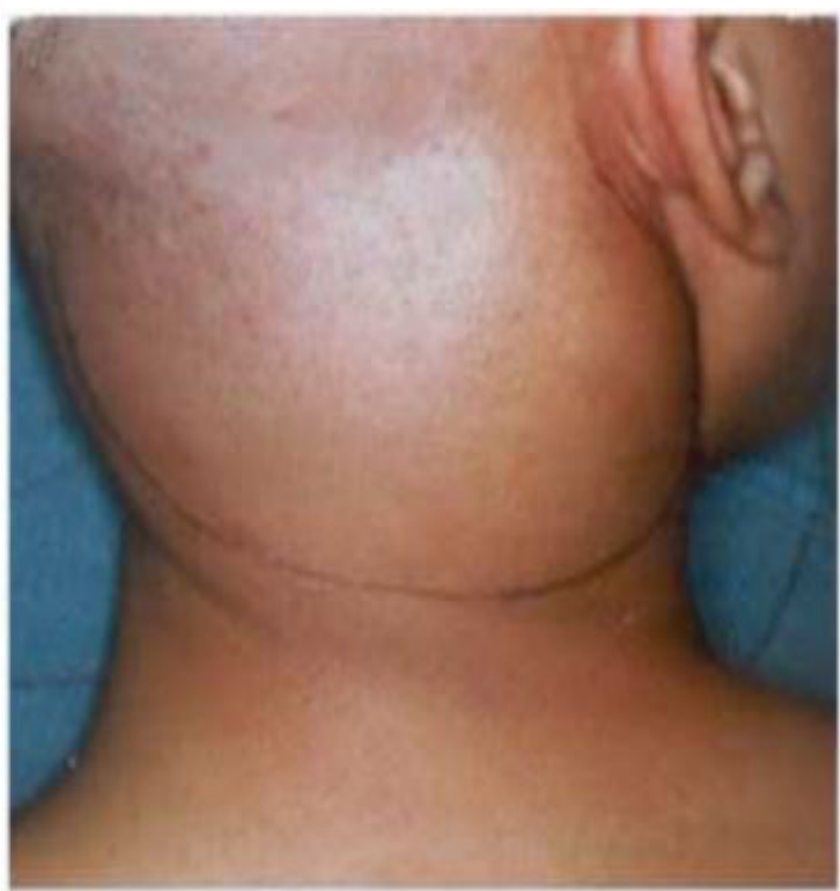

Figure 1: Rear view showing the clinical appearance of hydatid cyst of the posterior cervical region

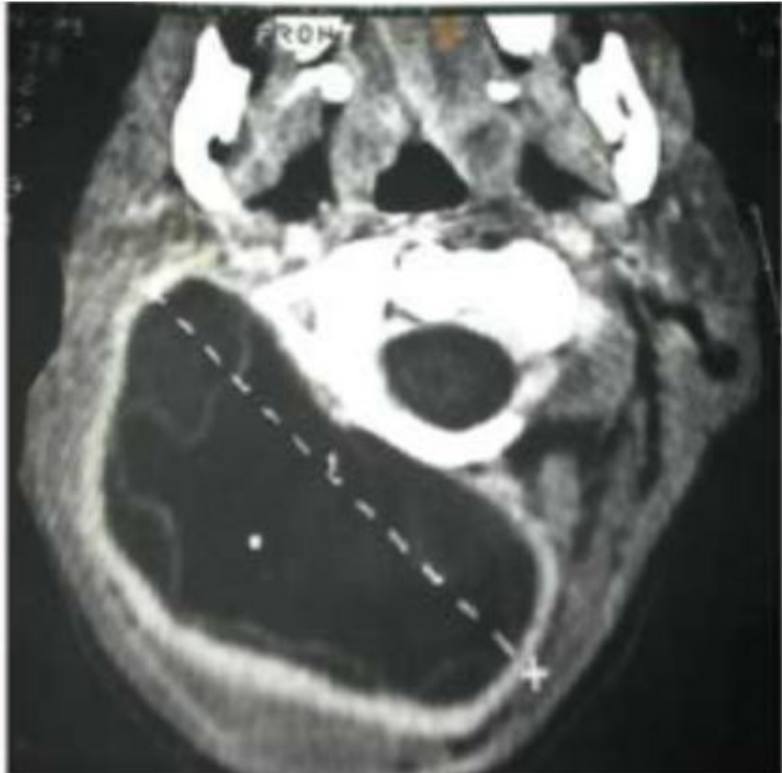

Figure 2: CT appearance of the posterior cervical hydatid cyst

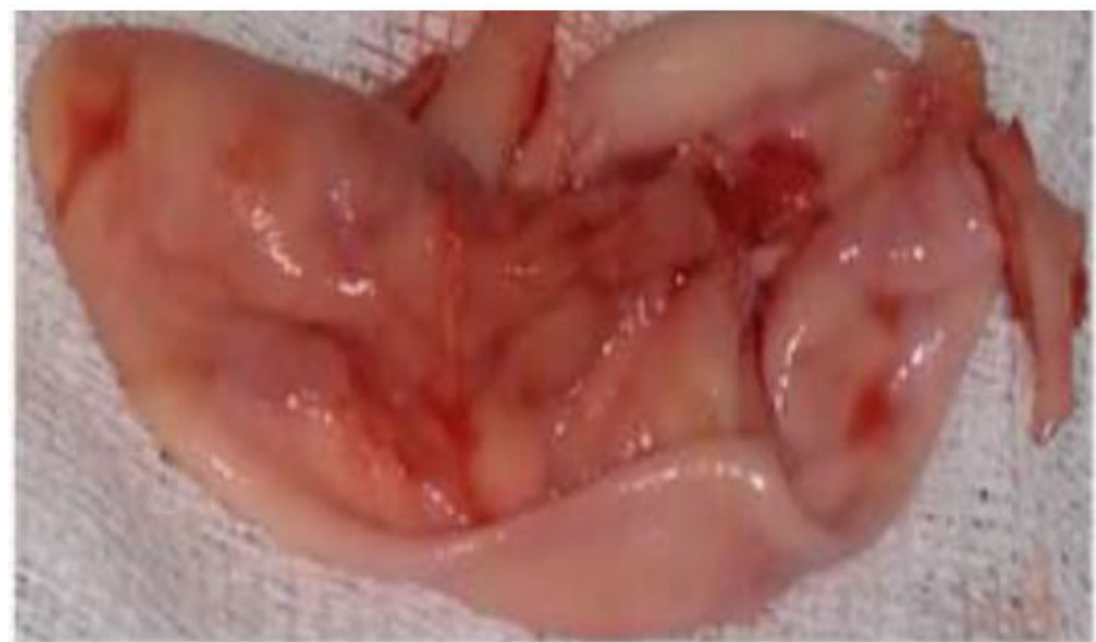

Figure 3: Macroscopic appearance of hydatid cyst after surgical excision 


\section{Discussion}

Although in Morocco it is not unusual to see hydatid cysts in common locations, such as the liver and lung, they are rare in the head and neck region. Only a few case reports are found in the literature [1,2]. Most hydatid cysts in the head and neck are asymptomatic, and symptoms depend on the location and size of a cyst. Authors emphasize the importance of the diagnosis of the rare locations. The main differential diagnoses are congenital cyst neck or cystic tumor [13]. Lesions are characteristically slow growing. A past medical history, family history, patient's occupation, and patient's residence may suggest a diagnosis of a hydatid cyst in differential diagnosis, but unless suspected or demonstrative radiologic findings are available, preoperative diagnosis may be missed [2]. When hydatid disease is found, patients must undergo careful complete systemic examination, especially to define hepatic and pulmonary lesions and other sites of involvement [3,4]. To confirm the diagnosis, serologic tests, including direct hemagglutination, latex agglutination, immunoelectrophoresis, skin tests, and enzyme-linked immunosorbent assay, are widely used. However, all serologic tests have low diagnostic sensitivity and specificity [3]. These tests become important in the followup of patients on treatment [6]. Today, the diagnosis of hydatid disease has been greatly facilitated with the use of USG, CT scan, and Magnetic Resonance Imaging (MRI). USG, which demonstrates the hydatid sands in purely cystic lesions as well as floating membranes, daughter cysts, and vesicles most clearly, is the method of choice for searching for the pathognomonic criteria of the hydatid cysts [13-16]. The fluid collection retains its well-defined contour but it is often less rounded, and appears to be « sagging " in places. The split wall may be localized in an area just outside the cyst, or it may become a "floating membrane" that is loose inside the cyst. This splitting of the wall, which is often discrete, must be systematically sought in any liquid collection, because it is almost pathognomonic for hydatic cyst [17]. Our patient was admitted in our ENT service with her CT entire body and we don't added RMi investigation. Surgery is the most important treatment for hydatid cyst. Hydatid cyst consists of 3 main layers; the outermost layer, which is the pericyst, occurs as a host reaction. The middle layer, the cuticular membrane, is an acellular membrane. The innermost layer is the germinative layer that produces the scolices. During the operation, the cyst should be removed with the germinative layer, carefully avoiding the spillage of the cystic contents. If the cystic contents spill out in the neck, the disease may transform into multiple hydatosis. In previously reported cases of hydatid cyst of the neck, cystotomy and subsequent excision of the pericystic tissue was performed. In parenchymal diseases such as a cyst of the lung, pericystic tissue can be left behind as a parenchyma-sparing procedure [1,2]. Combination of medical therapy with imidazole derivatives has been used in the management of patients with recurrence and high-risk contamination. Although there was no sign of any other organ involvement in our case, we treated the case with albendazole $(400 \mathrm{mg} / \mathrm{d})$ for 4 weeks postoperatively. Medical treatment may also be preferred if surgery is not possible, as in patients with multiple organ involvement, patients with a cyst in an inaccessible location, or patients with poor general condition and having unacceptable risk for surgery; however, the results are unpredictable [2,5]. Although the traditional choice of treatment for hydatid disease is surgery, in the recent literature, there are several reports on percutaneous treatment of abdominal and pulmonary hydatid cyst as an alternative to surgical treatment. They have reported lower rates of morbidity and mortality and less recurrence [18]. hydatid cyst should be treated with radical resection, with a wide margin of the healthy tissue. this may be difficult, but incomplete removal results in recurrence [19].

\section{Conclusion}

Although hydatid cyst rarely appears in the head and neck, a hydatid cyst of the neck should be considered in the differential diagnosis of cervical masses. Imaging techniques are reported to be highly contributive in hydatid cysts of the head and neck; however, in our case diagnosis could only be made with histopathology.

\section{References}

1. Katılmış H, Öztürkcan S, Özdemir I, Güvenç İA, Özturan Ş (2007) Primary Hydatid Cyst Of The neck. Amer J Otolaryn 28: 205-7.

2. Akal M, Kara M (2002) Primary hydatid cyst of the posterior cervical triangle. J Laryngol Otol 116: 153-5.

3. Tekin M, Osma U, Yaldiz M, Topcu I (1999) Preauricular hydatid cyst: an unusual location for echinoccosis. Eur Arch Otorhinolaryngol 261: 87-9.

4. Erog A, Atabekog S, Kocaog H (1999) Primary hydatid cyst of the neck. Eur Arch Otorhinolaryngol 256: 202-4.

5. Sennaroglu L, Onercĩ M, Turan E, Sungur A (1994) Infratemporal hydatid cyst--unusual location of echinococcosis. J Laryngol Otol 108: 601-3.

6. Turgut S, Ensari S, Katirci H, Celikkanat S (1997) Rare otolaryngologic presentation of hydatid cyst. Otolaryngol Head Neck Surg 117: 418-21.

7. Bouckaert MMR, Raubenheimer EJ, Jacobs FJ (2000) Maxillofacial hydatid cysts. Oral Surg Oral Med Oral Pathol Oral Radiol Endo 89: 338-42.

8. Bilgen C, Oner K, Ovül I, Kirazli T (2002) Vertebral hydatid disease presenting as a parapharyngeal and neck mass: a case report. Otolaryngol Head Neck Surg 126: 89-90.

9. Akhan O, Ensari S, Ozmen M (2002) Percutaneous treatment of a parotid gland hydatid cyst: a possible alternative to surgery. Eur Radiol 12: 597-9.

10. Goyal P, Ghosh S, Sehgal S, Panda I, Kumar A, et al (2014) Primary multilocular hydatid cyst of neck with unique presentation: a rare case report and literature review. Head Neck Pathol 8: 334-8.

11. Das S, Kalyani R, Kumar U, Kumar HM (2007) A varied presentation of hydatid cyst: a report of four cases with review of literature. Indian J Pathol Microbiol 50: $550-2$.

12. Chakrabarti I, Goswami BK (2012) Primary hydatid cyst of the neck diagnosed by aspiration cytology. Trop Parasitol 2: 127-8.

13. Belcadhi M, Kermani W, Mani R, Zeglaoui I, Ben Ali M, et al. (2011) Cervico-facial hydatidosis. Report of 17 cases. Tunis Med 89: $336-41$.

14. Cossu ML, Palermo M, Coppola M, Fais E, Ruggiu M, et al. (1999) A case of primary hydatidosis of the thyroid gland. Panminerva Med 24: 269-72.

15. Polat P, Kantarci M, Alper F, Suma S, Koruyucu MB, et al. (2003) Hydatid disease from head to toe. Radiographics 23: 475-94.

16. Alouini Mekki R, Mhiri Souei M, Allani M, Bahri M, Arifa N, et al. (2005) Hydatid cyst of soft tissues: MR imaging findings (Report of three cases). J Radiol 86: 421-5. 
17. Gharbi HA, Hassine W, Brauner MW, Dupuch K (1981) Ultrasound examination of the hydatic liver. Radiology 139: 459-63.

18. Knoch H, Helbig M, Schirren J, Tasman AJ (1999) Cystic space-occupying lesion of the neck soft tissues: cave echinococcosis. HNO 47: 188-91.

19. Chaturvedi S, Gupta S, Faujdar M, Gupta G, Patel J, et al. (2015) Hydatid Cyst in Femur: A Rare Case Report. Ann Pathol Lab Med 2: c180-2. 